\title{
Analysis of fatigue test data to reassess EN 1993-1-9 detail categories
}

This paper addresses the assessment of fatigue details according to EN 1993-1-9, which form the basis of the most important fatigue verification, the nominal stress approach. First of all, a suitable statistical methodology had to be defined for consistent detail classification. A structured database on the MySOL platform serves as a basis for the evaluation of the detail categories. In addition to fatigue test data documented in the background document to EN 1993-1-9, this database also includes new test data provided by the authors. After selecting the most meaningful test data, important details, such as longitudinal welds, were reassessed. In addition, the authors carried out fatigue tests in connection with numerical simulations in order to be able to evaluate the fatigue strength with better accuracy. The results so far show that the details analysed often prove to have a higher fatigue strength than currently documented in EN 1993-1-9.

Keywords fatigue tests; fatigue detail catalogue; fatigue detail classification; effective notch stress concept; prediction interval

1

\section{Motivation}

In many applications, e.g. bridges, cranes, masts, towers, fatigue verification of the steel structure is required and is essential for design. However, the detail catalogue in EN 1993-1-9 [1] leads to partly conservative and uneconomical results compared with former national standards such as DIN 4132 [2] or DS 804 [3] (see also the report of a common research project [4]). One of the reasons for this is a change in concept which has been reduced to checking stress ranges only and a less refined detail catalogue. In addition, the background to the detail catalogue has proved to consist of an incomplete database, which often goes back several decades. The evaluation methods utilized at that time are partially inconsistent. For these reasons, the investigations described here are aimed at analysing existing experimental data together with new experimental data for statistical purposes in order to develop recommendations for improved detail categories also for European standardization. To this end, a detailed database structure was developed in order to be able to evaluate the fatigue test data in an intelligent way. The database application enables search and selection functions as well as a user-controlled evaluation of the test

This is an open access article under the terms of the Creative Commons Attribution License, which permits use, distribution and reproduction in any medium, provided the original work is properly cited. data. Based on the primary sources gathered, many relevant influences that affect the fatigue strength were identified and included in the database as additional information.

Current research activities $[5,6,7,8,9,10]$ have reassessed the details of EN 1993-1-9 [1]. This paper demonstrates the evaluation of selected details such as cruciform joints and longitudinal welds. Furthermore, first results from additional experimental and numerical investigations of endplate connections are presented.

Statistical assessment method and evaluation of significant influencing factors

\subsection{Overview}

Experimental test data always show random scatter. Unavoidable sample-to-sample variations of influencing factors such as surface defects at weld toes, internal defects in weld roots, geometrical tolerances and metallurgical inhomogeneities lead to this scatter, even under identical test conditions. For the assessment of a characteristic fatigue strength, this scatter should be taken into account; however, there are different approaches to the statistical analysis [11, 12, 13, 14, 15].

The approaches differ in terms of the definition of the resistance model for fatigue strength, the assumed probability function and the consideration of the sample size. EN 1990 [16] defines the reliability and safety concept of all Eurocodes for structural design. The informative Annex D of EN 1990 contains rules for design assisted by testing.

\subsection{Resistance model and regression analysis}

For high-cycle fatigue of steel structures, the relation between the applied stress range $S$ and the corresponding number of stress cycles to failure $N$ follows an exponential law [17]. On a log-log scale with decimal logarithm, the test data can generally be allocated to a straight line, see Fig. 1, expressing a log-linear dependency of stress cycles on the stress range, Eq. (1):

$$
\log N=\log a-m \cdot \log S
$$

Fig. 1 shows the log-linear relationship in the finite life region. According to EN 1993-1-9 [1], the finite life region 


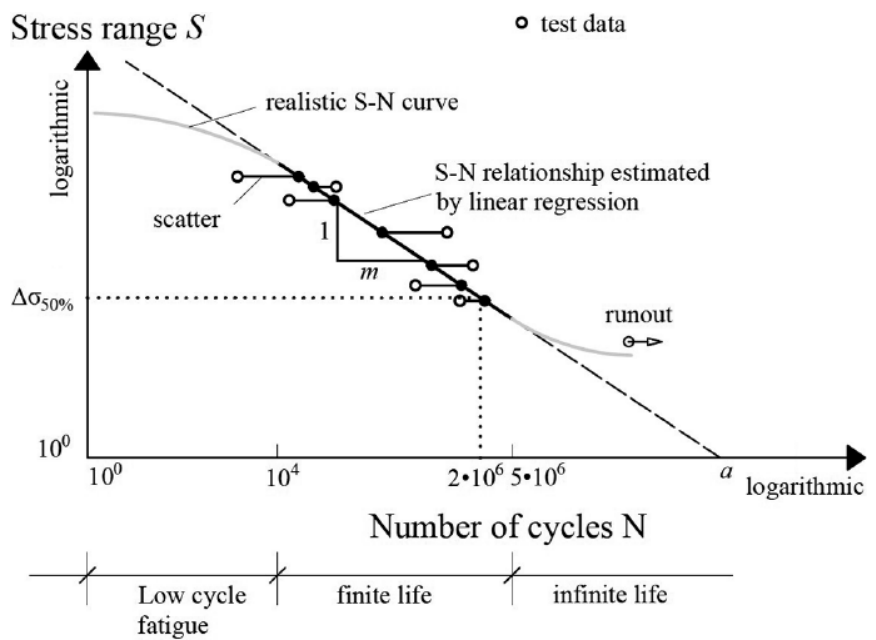

Fig. 1 Log-linear dependency of number of stress cycles on stress range

is located between $10^{4}$ and $5 \cdot 10^{6}$ stress cycles. The $S-N$ curve corresponds to the resistance model. The parameters $a$ (intercept of $S-N$ curve of finite life region on horizontal axis $S=10^{0}=1$ ) and $m$ (slope of $S$ - $N$ curve) in Eq. (1) can be calculated using a regression analysis. Since both parameters are estimated based on the information provided by a limited number of fatigue tests, they have to be replaced by the estimates $\hat{a}$ and $\hat{m}$ If the slope $m$ of the $S-N$ curve is known from previous information (e.g. $m=3$ for welded details with sharp notches [18]), $\hat{a}$, or rather $\log \hat{a}$, is given by Eq. (2). Test specimens that have not reached a defined failure criterion (runouts) must not be taken into account.

$$
\log \hat{a}=\frac{1}{n} \cdot\left(\sum \log N_{\mathrm{i}}+m \cdot \sum \log S_{\mathrm{i}}\right)
$$

where $n$ is the sample size (number of fatigue tests data) and $i$ is the index of the single fatigue test. The standard deviation $s$ of the population is either known or unknown. In the latter case it is estimated from the sample. The standard deviation $s$ in terms of $\log N$ amounts to

$$
s=\sqrt{\frac{\sum\left[\log N_{\mathrm{i}}-\left(\log \hat{a}-m \log S_{\mathrm{i}}\right)\right]^{2}}{n-1}}
$$

\subsection{Distribution and prediction interval}

Eurocode 0 [16] implicitly assumes that the distribution of the population is normal or log normal. As there is no prior knowledge about the mean, it is estimated from the sample. In the case where the slope $m$ is forced to be a certain value and does not have to be estimated from the sample, EN 1990, Annex D.7, is applicable for the derivation of a characteristic $S-N$ curve.

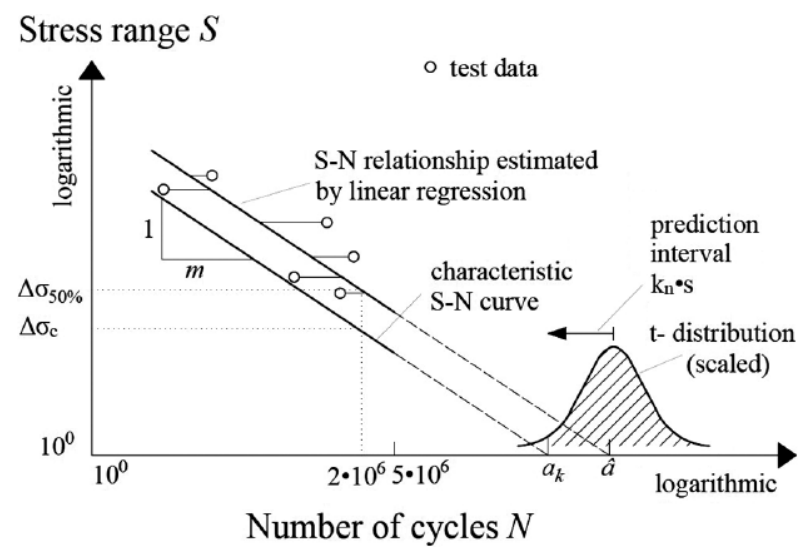

Fig. 2 Schematic procedure for the statistical evaluation of test data

According to EN 1990, the coefficient $k_{\mathrm{n}}$ is a factor that can be used to derive characteristic values with $95 \%$ probability of survival, see Tab. 1.

When the standard deviation is estimated from the sample according to Eq. (3), the lower row of Tab. 1 must be used.

The $k_{\mathrm{n}}$ factors are based on the prediction method of fractile estimation (prediction interval) [20]. The characteristic value of the intercept $a_{\mathrm{k}}$ is obtained from Eq. (2). The procedure is shown schematically in Fig. 2 .

$$
\log a_{\mathrm{k}}=\log \hat{a}-k_{\mathrm{n}} \cdot s
$$

The characteristic reference value $\Delta \sigma_{\mathrm{c}}$ of the fatigue strength at $2 \cdot 10^{6}$ stress cycles can be determined as given in Eqs. (5) and (6):

$$
\begin{aligned}
& \log S=\frac{\log 2 \cdot 10^{6}-\log a_{\mathrm{k}}}{-m} \\
& \Delta \sigma_{\mathrm{c}}=10^{\log S}
\end{aligned}
$$

The procedure described meets the requirements of background document 9.01 [11] to EN 1993-1-9 [1] and EN 1990, Annex D [16], as has been demonstrated in [4].

\subsection{Evaluation of significant influencing factors}

One of the main objectives of the research project presented here [5] was the evaluation of factors influencing the fatigue strength, such as parameters on the resistance side, e.g. yield strength, as well as parameters on the action side, such as the mean stress or the $R$ ratio between minimum and maximum cyclic stresses. There are differ-

Tab. $1 \quad k_{\mathrm{n}}$ factor for characteristic values with $95 \%$ survival probability (according to Eurocode 0 [16])

\begin{tabular}{llllllllllll}
\hline $\mathbf{n}$ & $\mathbf{1}$ & $\mathbf{2}$ & $\mathbf{3}$ & $\mathbf{4}$ & $\mathbf{5}$ & $\mathbf{6}$ & $\mathbf{8}$ & $\mathbf{1 0}$ & $\mathbf{2 0}$ & $\mathbf{3 0}$ & $\boldsymbol{\infty}$ \\
\hline$s$ known & 2.31 & 2.01 & 1.89 & 1.83 & 1.80 & 1.77 & 1.74 & 1.72 & 1.68 & 1.67 & 1.64 \\
$s$ unknown & - & - & 3.37 & 2.63 & 2.33 & 2.18 & 2.00 & 1.92 & 1.76 & 1.73 & 1.64 \\
\hline
\end{tabular}




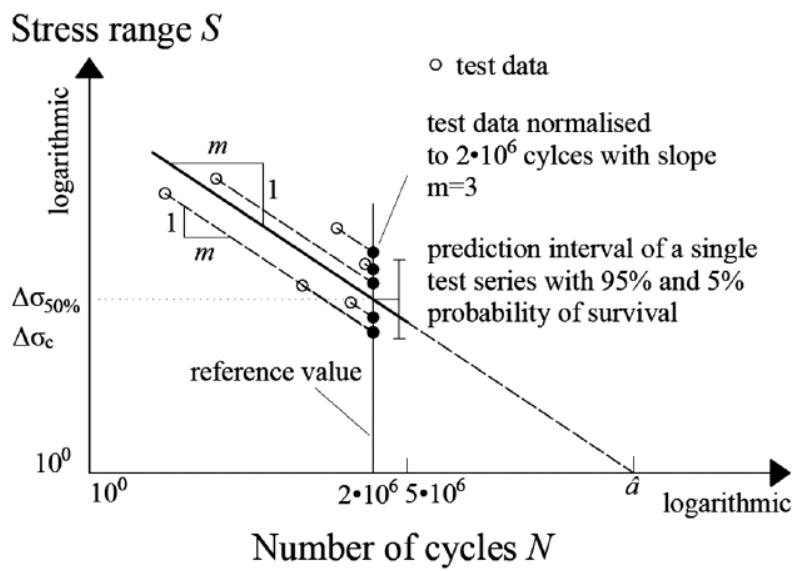

Fig. 3 Determination of normalized test data (scaled to 2 million cycles)

ent approaches to assessing significant influences on the fatigue strength based on experimental data.

A simple approach for examining influencing factors is to group them. To check, for example, the influence of the yield strength on a specific constructional detail, all test results on mild steel are evaluated together in a group and compared with the results of the tests on high-strength steel. A statistical hypothesis test such as a $t$ test helps to assess whether the influence is significant.

The evaluation of normalized data is another appropriate approach for identifying significant influences on the fatigue strength. In this method the statistical uncertainty in the $S$ - $N$ curve slope $m$ is neglected and all data are projected along the line with a fixed slope $m$ to the axis of $N=2 \cdot 10^{6}$ cycles, see Fig. 3. As the data are standardized to 2 million cycles, the ordinate axis is directly comparable with the fatigue reference value $\Delta \sigma_{\mathrm{C}}$. The normalized fatigue test data can then be shown depending on a potential influencing parameter such as the yield strength, as shown in Fig. 4.

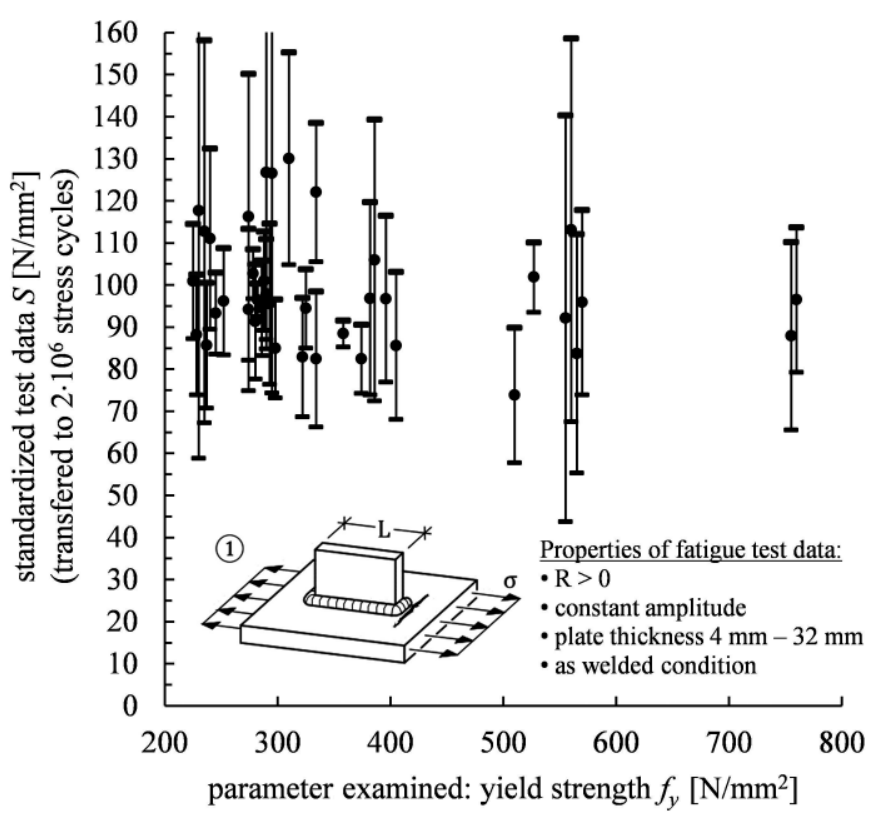

Fig. 4 Standardized scatter bands with $5 \%$ and $95 \%$ survival probability as a function of the yield stress for test data on longitudinal attachment (test data normalized to 2 million cycles)
Fig. 4 shows the fatigue strength of tests on longitudinal attachments depending on the yield strength. Each scatter band represents a test series. If the parameter examined exerts a significant influence on the fatigue strength, the interval should show a tendency to go up or down. As no tendency can be recognized for the mean or the scatter band, the yield strength is probably not influencing the fatigue strength of longitudinal attachments.

In order to work with normalized data, the test results should not be modified by other significant influencing factors. Therefore, it is advisable to use only test data with a comparable stress ratio $R$, since pulsating compressive stresses may have a positive influence on the fatigue strength. For the Eurocode evaluation, a further condition is to keep the slope of the $S-N$ curves constant for all test series, although the slope may differ for some details. For example, post-weld treatments may lead to deviating slopes of the $S-N$ curve.

\section{Fatigue test data and database structure}

The data collected are based on several fatigue data collections gathered during previous research [21, 22] derived from 13 individual databases of different international authors.

First, the original primary sources of all data collections were acquired and analysed again in detail. Additionally, the authors' own experimental data from the institutions involved as well as additional published experimental data not yet included in the data collections were added to the database. The innovative database based on Structured Query Language (SQL) currently contains over 400 primary sources with about 1970 fatigue series and about 22000 individual test results on various details. About $23 \%$ of these data can be distinguished as newly integrated in addition to the known data of the former data collections. The database developed aims to include all relevant information regarding the fatigue strength by means of approximately 140 input fields. These include the following information:

- General information: detail, source, general remarks

- Load data: type of load, test frequency, position of calculated stress range

- Material information: steel grade, yield strength, tensile strength

- Information on welds: shape, welding symbols according to [23], number of layers, pre-treatment, posttreatment, welding sequence, properties of filler metal, welding position according to [24], process according to [25]

- Environmental conditions: temperature, corrosive conditions, humidity

- Detail-specific properties: dependent on the detail (e.g. thickness of test specimens, span)

- Test results: stress range, stress ratio, number of cycles to failure, failure criterion, failure region 
With the help of the structured information included in the database and the web-based evaluation tool, it is easy to evaluate fatigue tests and their influencing variables. The first re-evaluations of detail categories have already been carried out. The focus is on the basic details of Tables 8.2 to 8.5 [1], which contain "welded built-up sections", "transverse butt welds", "welded attachments and stiffeners" and "load-carrying welded joints". The database results of the detail classification of longitudinal welds in various design variants are presented as an example in section 4. In addition, first results of the re-evaluation of the test data of the database in combination with the authors' own test data for the cruciform and T-joint obtained experimentally are presented in section 5 .

Fatigue evaluation of longitudinal weld details using the database

\subsection{Filtering of data}

The analysis of the fatigue test series showed a largely varying data quality. Some sources are secondary sources and contain little detailed information about the geometry or specimen material, so associated primary sources were needed to extract all the properties of the test series. However, in primary publications too, some essential information such as weld details or failure criteria are insufficiently described. In addition, the documented failure criteria vary greatly. In some cases, test results are presented only graphically in moderate quality. In addition, some series of the existing data collection may appear to have been assigned to a wrong detail in earlier evaluations, which in some cases could only be determined after studying the original publications. Furthermore, for several experimental data series it was not possible to assign a detail clearly according to EN 1993-1-9 [1] due to lack of essential information.

Tab. 2 gives an overview of all series and tests of longitudinal welds, such as automatic and manual welds or intermittent longitudinal fillet welds.
In order to achieve a consistent detail classification, only meaningful data have been considered. The following main data filtering criteria were applied:

- Availability of primary sources

- Availability of test data in table or diagram form

- Validity of the failure criterion

- Number of tests

- Clear assignment to a fatigue detail of EN 1993-1-9 [1].

\subsection{Evaluation of test results}

The following section presents the new evaluation of fatigue details 2, 3 and 5 of Tab. 8.2 [1], which comprise the classic longitudinal welds for different executions, see Tab. 3. Detail 2 with detail category FAT 125 refers to an automatic fillet weld, which should not have any stop/ start positions or whose stop/start positions have been properly 'repaired'. Detail 3 belonging to FAT 112 includes automatic fillet or butt welds carried out from both sides but including stop/start positions. Manual fillet or butt welds belong to detail 5 and FAT 100 . The detail categories specify the reference values of the fatigue strength $\Delta \sigma_{\mathrm{C}}$ for $N_{\mathrm{C}}=2 \cdot 10^{6}$ cycles.

The analysis of the data revealed that the presence of stop/ start positions is not always documented. So, the assignment to detail 2 or detail 3 is not clear. Therefore, different approaches were investigated: the series with unknown information on stop/start positions (184 test results) were evaluated once with all data safely assigned to detail 2 and once with all data safely assigned to detail 3 .

After selecting the data, three series with a total of 54 tests were used to evaluate detail 2 , all based on the investigations of Fisher [26]. Eight series with a total of 184 tests carried out by Reemsnyder [27], Olivier and Ritter [28] and Minner [29] were used to evaluate detail 3, including test data where information on stop/start positions is not available. For detail 5 , four meaningful series with 39 tests

Tab. 2 Fatigue test series on welded built-up sections (Tab. 8.2 [1])

\begin{tabular}{llll}
\hline Detail & Description & $\begin{array}{l}\text { Number of } \\
\text { series }\end{array}$ & $\begin{array}{l}\text { Number of } \\
\text { tests }\end{array}$ \\
\hline (2) & Automatic fillet welds & 6 & 77 \\
(3) & Automatic fillet or butt weld carried out from both sides but including stop/start positions & 28 & 305 \\
(5) & Manual fillet or butt weld & 13 & 129 \\
(8) & Intermittent longitudinal fillet welds & 7 & 38 \\
(9) & Longitudinal butt, fillet or intermittent weld with a cope hole height not greater than 60 mm & 7 & 36 \\
(10) & Longitudinal butt weld, both sides ground flush parallel to load direction, 100\% NDT & 2 & 183 \\
& No grinding and no start/stop & 1 & 100 \\
& with start/stop positions & - & - \\
(11) & Automatic longitudinal seam weld in hollow sections & 1 & 7 \\
\hline Total & & 65 & 875
\end{tabular}




\begin{tabular}{ll}
\hline Detail category & Description/Requirements \\
\hline 125 & $\begin{array}{l}\text { 2) Automatic fillet welds. No stop/start position is permitted except } \\
\text { when the repair is performed by a specialist and inspection is carried out } \\
\text { to verify the proper execution of the repair. }\end{array}$ \\
\hline
\end{tabular}

112

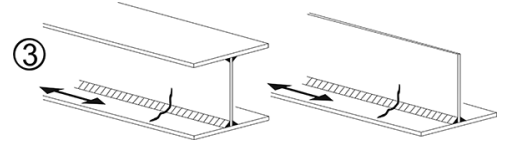

3) Automatic fillet or butt weld carried out from both sides but including stop/start positions.

100

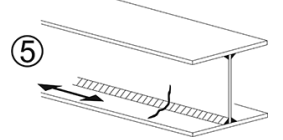

5) Manual fillet or butt weld

were evaluated, which result from investigations by Olivier and Ritter [28, 30], Munse and Stallmeyer [31] and Ruge and Woesle [32]. Different failure criteria were used in the different reporting. Nevertheless, despite the lack of common criteria, the number of cycles to failure was determined for the evaluation. Moreover, the test series include different scales of specimens, different welding processes and show metallurgical specifics, geometric tolerances and residual stresses or weld seam irregularities. On the one hand this variety leads to a large scatter of the data, but on the other, also to a larger representation of the results. The left-hand diagram in Fig. 5 presents the filtered test results, see section 4.1, in comparison to all test results of detail 3, including test data where information on stop/start positions is not available.

For the fatigue assessment, all the filtered test results of one detail were evaluated together. In a first step, a linear regression was performed using the defined inverse slope $m=3$. In addition, the reference value of the fatigue strength $\Delta \sigma_{\mathrm{C}}$ was determined based on the $S-N$ curve calculated using the prediction interval, see section 2.3. The right-hand diagram in Fig. 5 presents the $S-N$ curve for detail 3 based on the filtered test results, including test data where information on stop/start positions is not available.

The fatigue class assessment of the three details under consideration is presented in Tab. 4.

First, it can be seen that the incorporation of the data with no information on stop/start positions has a great influence on the result of the fatigue evaluation. The assignment of detail 2 to FAT class 125 seems reasonable in all cases. The evaluation of detail 3 reveals a fatigue strength of 119 at least, which is higher than the currently prescribed FAT class 112 in EN 1993-1-9 [1]. Owing to the unknown information on stop/start positions in a considerable amount of data, an upgrade of the FAT class for detail 3 has to be investigated in future fatigue tests series.

However, the evaluation of the manual welds, detail 5, results in a fatigue strength reference value $\Delta \sigma_{\mathrm{C}}=119 \mathrm{MPa}$, so that FAT 112 can be achieved instead of FAT 100, as currently documented in EN 1993-1-9 [1].
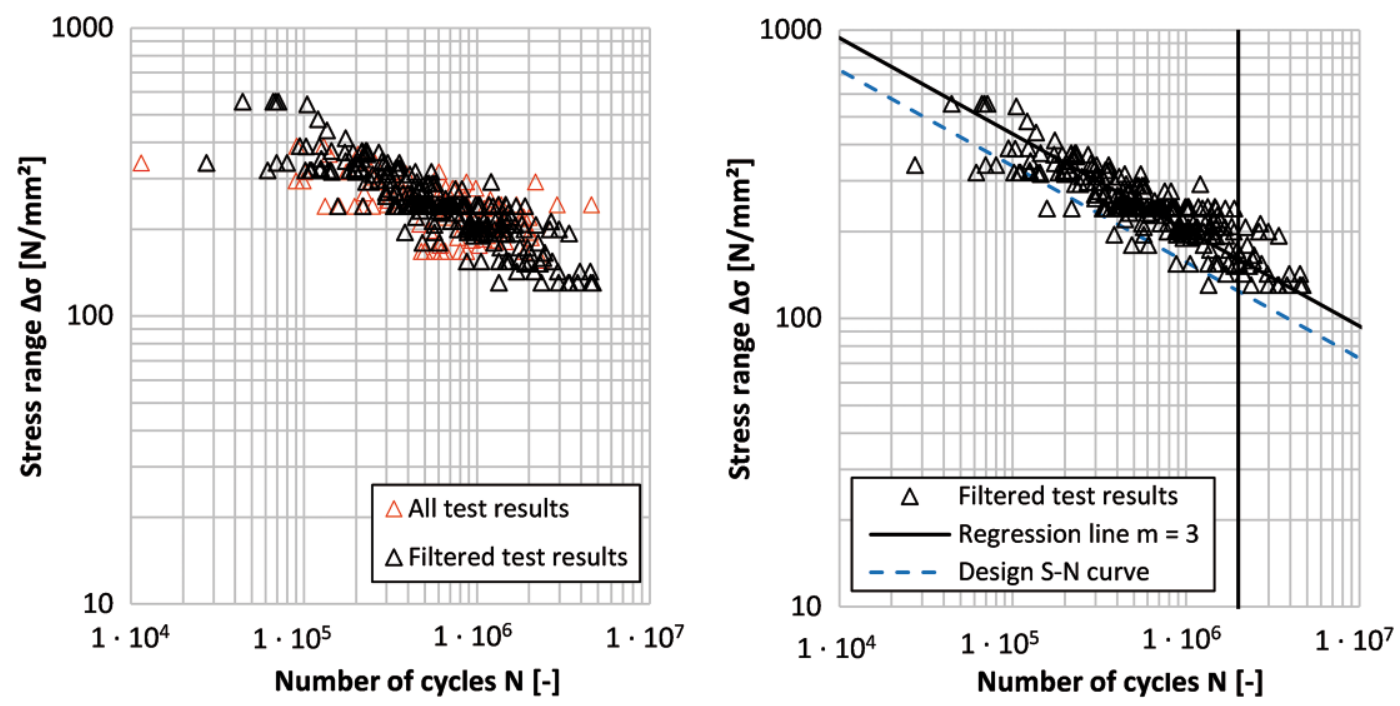

Fig. 5 All test results and filtered test results for detail 3 of Tab. 8.2 [1] (left) and design S-N curve for detail 3 (right) 
Tab. 4 Fatigue evaluation of details 2, 3 and 5 of Tab. 8.2 [1] based on different approaches

Details and assignment of test data to details

Detail 2 (specimens without stop/start positions)

Detail 2 (specimens without stop/start positions and specimens with unknown information on stop/start positions)

Detail 3 (specimens with stop/start positions)

Detail 3 (specimens with stop/start positions and specimens with unknown information on stop/start positions)

Fatigue evaluation of welded joint details using the authors' own experimental and numerical investigations in combination with the database

\subsection{Motivation}

In addition to the re-evaluation of the fatigue details, see the example presented in section 4 , there is a need for further experimental investigations of some details. In addition to investigations of cover plates [33], this also applies to the endplate connection with prestressed bolts. This detail represents an economical and easy-to-assemble joint in steel construction practice, e.g. for crane runways subjected to high fatigue loading.

However, the fatigue design of an endplate connection has so far been insufficiently dealt with in EN 1993-1-9 [1]. The welds connecting beam to endplate should be verified in accordance with Tab. 8.5 of the code [1]. In any case, weld toe failure is considered in accordance with detail 1 or 2 of full or partial penetration welds, see Fig. 10. The two details belong to the same detail categories, including length and size effects, and differ only in the assumption of a "flexible panel" in the case of detail 2, which must be verified with modified nominal stresses. However, the code does not give any indication as to where the user has to assume a flexible endplate. Modified nominal stresses require extensive numerical simulations. The selection of the correct detail is therefore crucial for the designer. If the welds are not full penetration or fillet welds, a failure of the weld root according to detail 3 should be considered in addition to the verification of the weld toe.
Apart from the welds, the bolt represents the second critical detail of the joint. In order to verify the bolt, the standard requires the calculation of the true bolt force while considering prying forces and bending stresses from other sources. At this point again, specific information for determining the stresses is missing. The weld and bolt stresses during fatigue loading of endplate connections were examined in more detail within the scope of the investigations in [5] in order to clarify the unanswered questions regarding their fatigue design.

Firstly, full-size joint tests were carried out on rolled sections with different endplate connections (see Fig. 6, left). Additionally, parts of the endplate connections in the form of T- and L-joints with similar dimensions were investigated experimentally in order to check the transferability between large- and small-scale tests (see Fig. 6, right).

The following sections give a brief overview of the ongoing investigations. Please refer to $[5,9]$ for more detailed information.

\subsection{Experimental investigations}

This section deals with experimental tests on connections with overhanging endplates in the form of large-scale joint tests and small-scale tests on T-joints. One series deals with fillet welds in the connection between web and flange (series B) in the tension area. The second series comprises specimens with butt welds (series C).
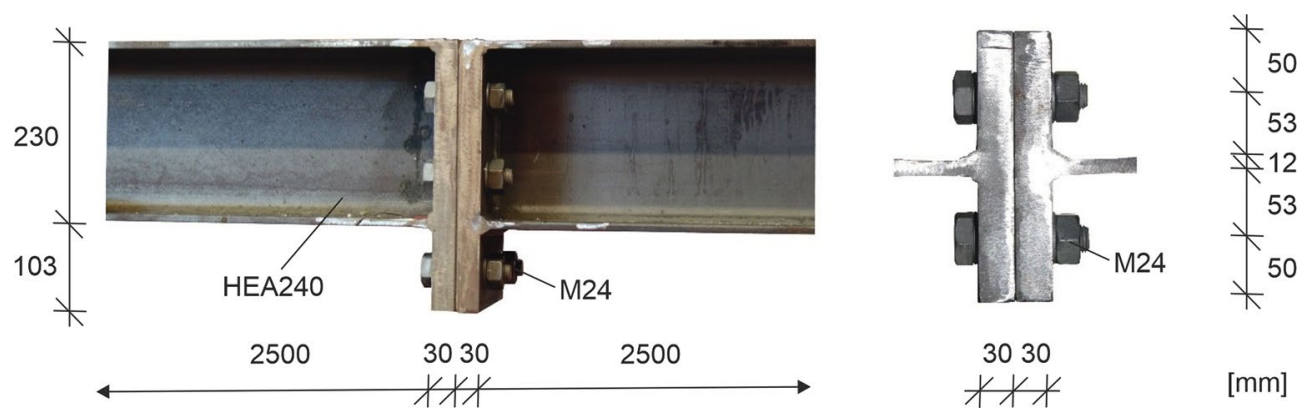

Fig. 6 Examples of specimens for large-scale tests (left) and small-scale tests (right) 

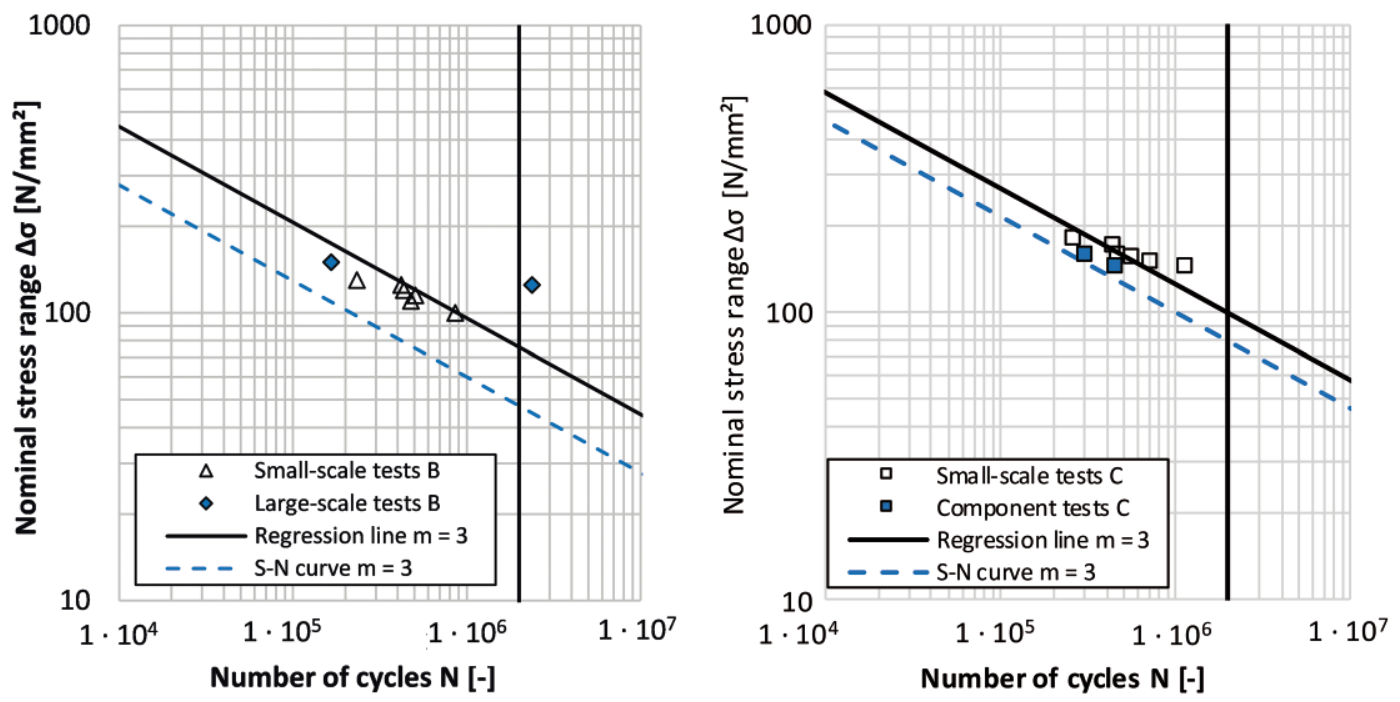

Fig. 7 Test results and evaluation of large- and small-scale tests of series B with fillet welds (left) and series $\mathrm{C}$ with butt welds (right)

The endplate connections and T-joints with butt welds and potential failure at the weld toe belong to FAT 80 (detail 1 or 2 of Tab. 8.5 [1]). In this case the detail catalogue requires a verification with modified nominal stress ranges in the case of a "flexible panel" (detail 2). Since no criterion for the deformability of the plate is specified, nominal stresses are considered first. For the specimens with fillet welds, the failure of the weld root theoretically governs, which corresponds to detail 3 of Tab. 8.5 with FAT 36* [1]. The welds were produced by metal active gas welding (MAG). During testing, a constant stress ratio $R=0.1$ was applied.

Fig. 7 shows the test results and the $S-N$ curves of both series containing small-scale and large-scale tests, calculated with the prediction interval, as explained in section 2. The evaluation of series $\mathrm{C}$ leads to a result $\Delta \sigma_{\mathrm{C}}=78.2 \mathrm{MPa}$ for the failure at the weld toe, without considering modified nominal stresses. As expected, the evaluation provides a lower fatigue strength $\Delta \sigma_{\mathrm{C}}=47.6 \mathrm{MPa}$ for the failure of the weld root, which could be observed for all specimens in series B. However, it should be mentioned that the fatigue strength of the weld root is influenced by numerous factors (see section 5.4.1), which makes it difficult to predict accurately the fatigue strength of this detail. Therefore, the test results are to be supplemented by and compared with further test results from the literature incorporated in the database, which may lead to lower evaluations, see section 5.4 .

Additionally, it can be seen in Fig. 7 that large-scale tests downgrade the fatigue strength of the small-scale test results in the case of both details. Regarding detail 1 in series $\mathrm{C}$, both beam test results have a lower fatigue strength than that of the corresponding small-scale tests. For detail 3 and series $\mathrm{B}$, the beam tests do not necessarily show a lower fatigue strength but downgrade the result by increasing the scatter. Owing to the web of the rolled section at the endplate connection, the large-scale tests lack symmetrical load distribution on both sides of the tension flange, compared with the small-scale specimens. Another reason for a lower fatigue strength in the large-scale tests is the fabrication, leading to higher residual stresses due to the welding of larger specimens. Owing to the larger amount of weld volume, internal and surface defects are also more likely in larger structures. In summary, it can be stated that small-scale tests are not sufficient for a fatigue class evaluation of details in endplate connections and should always be supplemented by tests on fullsize specimens. However, it should be mentioned that the underlying test results reflect a small sample. In future, the conclusions drawn should be supplemented by additional test data.

\subsection{Numerical investigations}

After the experimental investigations were carried out, they were numerically recalculated for the validation of numerical models. With the help of validated models, a parametric study can be performed to derive bolt force and weld stress functions for any T-joint or endplate connection geometry. Parametric ABAQUS models were created for both large- and small-scale tests. The effective notch stress concept $[34,35]$ was utilized to determine numerically the fatigue strength of the weld root and toe. To do this, the actual weld contour is replaced by an effective one, i.e. a notch radius is modelled at the weld toe and root. In order to comply with the requirements of the IIW recommendations for the present thickness range, a radius of $1 \mathrm{~mm}$ and an element size of $<1 / 6 \mathrm{~mm}$ in the radii were applied [35]. The maximum principal stress at the radius represents the effective notch stress. The resistance is determined by a single $S$ - $N$ curve with FAT 225 and the inverse slope $m=3$ [35].

In order to enable the necessary fine discretization of the model, the relevant section of the specimen is simulated by a sub-model, which, due to its smaller size, can be meshed much more finely compared with the global model. The results of two sub-model simulations are illus- 

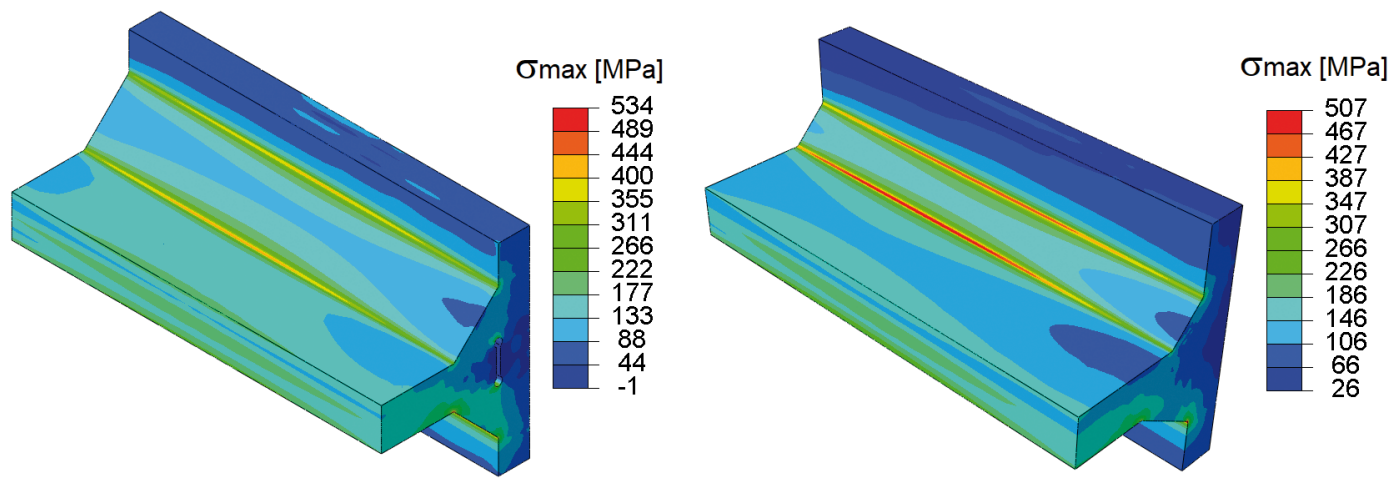

Fig. 8 Maximum effective notch stresses (principal stresses) in the sub-models of one large-scale model B (left) and C (right)
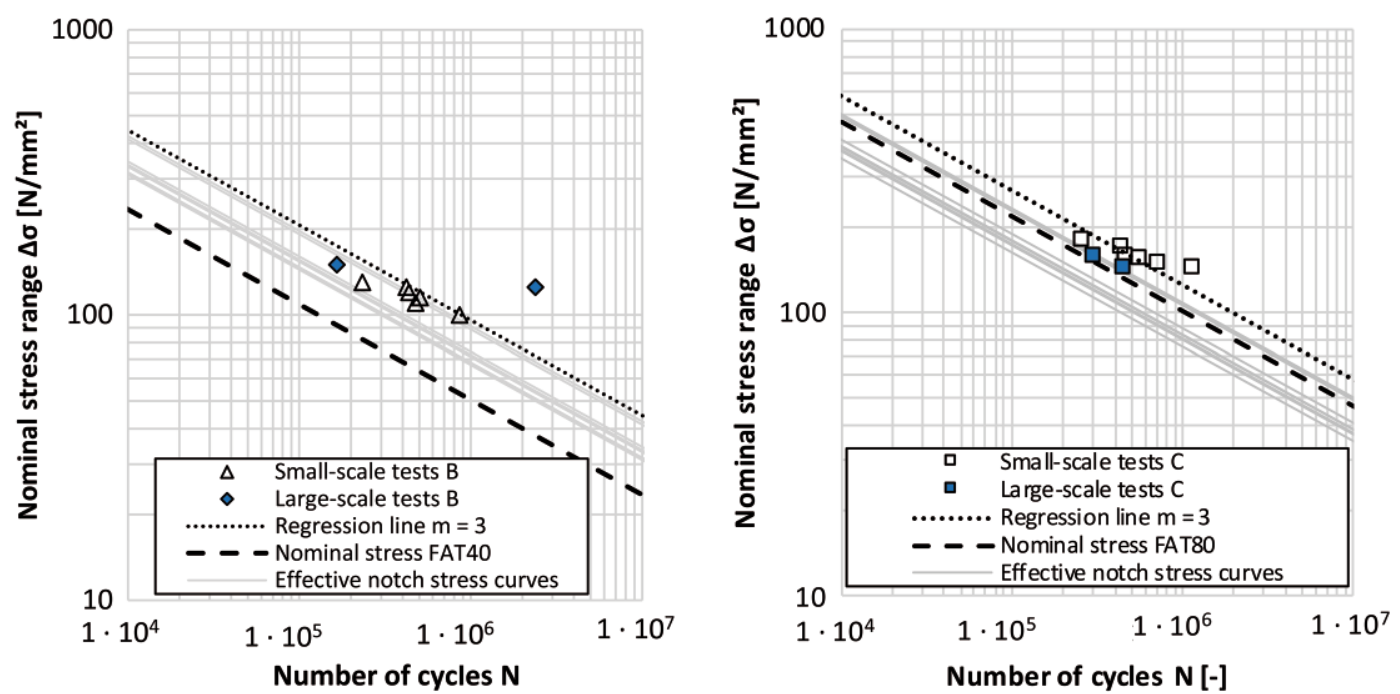

Fig. 9 Results of fatigue tests and prediction of cycles using the nominal and effective notch stress concepts of series B with fillet welds (left) and series C with butt welds (right)

trated in Fig. 8 in terms of principal stresses. The effective notch stress range of $353 \mathrm{MPa}$ (after subtracting stresses introduced during bolt prestressing) occurs in model B in the weld root. In model $C$ the effective notch stress range at the weld toe governs, with a value of $423 \mathrm{MPa}$. Both most critical spots comply with the crack initiation during the tests.

Fig. 9 presents a comparison of number of cycles obtained from experimental tests and calculation using the nominal stress concept and effective notch stress approach. Owing to the different true bolt prestress forces and the non-linear bolt force progression in relation to external forces on the specimen, not just one but slightly different effective notch stress curves occur. For a failure in the weld root of series B, the nominal stress approach leads to the most conservative results, see lowest line in left-hand diagram of Fig. 9. The notch stress concept results in more economical and realistic numbers of cycles. Regarding the prediction of failures at the weld toe in series $\mathrm{C}$, the effective notch stress approach results in a more conservative $S$ - $N$ curve than the nominal stress concept, see right-hand diagram in Fig. 9.

This result indicates that the application of effective notch stresses or modified nominal stresses (referring to detail 2 of Tab. 8.5 [1]) is necessary for the fatigue verification at the weld toe of endplate connections, which leads to more conservative results.

The size influence of EC3-1-9 does not play a major role in endplate connections because even with larger joint dimensions, the second size level (thickness of plate and distance to weld toe $>50 \mathrm{~mm}$ ) is seldom reached.

\subsection{Integration of new experimental test data into database}

\subsubsection{Details of experimental programme}

As already described, the current version of EN 1993-1-9 [1] does not contain specific construction details for endplate connections. Therefore, using the nominal stress concept, design engineers have no choice but to apply the basic detail 1 (cruciform and T-joint with weld toe failure - Fig. 10, left) and detail 3 (cruciform and T-joint with weld root failure - Fig. 10, right). For these two standard details, numerous test data were collected, categorized and re-evaluated as part of the research project [5]. Except for the full penetration joint variant, the competing crack initiation at weld toe and weld root can be described as a 


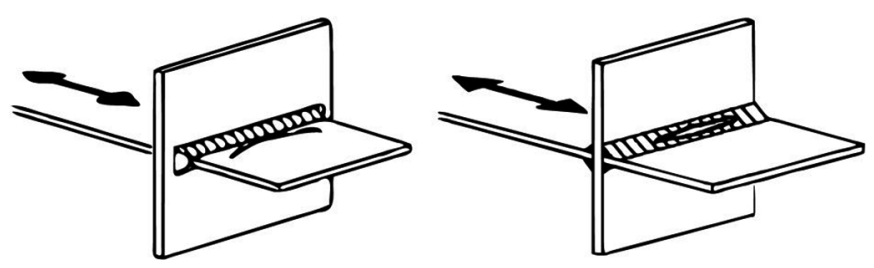

Fig. 10 Different failure modes for cruciform and T-joints: weld toe (left) and weld root failure (right) [1]

specific feature of these joints. EN 1993-1-9 [1] considers this through the verification for at least two details, namely, detail 1 (weld toe failure) and detail 3 (weld root failure). A critical crack initiation at the weld toe (detail 1) is currently evaluated depending on the geometry, i.e. plate thickness $t$ and distance between the weld toes $l$ with a fine-graded classification from FAT 80 to FAT 40, based on the baseplate cross-section. However, a weld root failure (detail 3) is assessed with FAT 36* regardless of the joint's geometry, based on the weld cross-section. For both details, the following sections present filtered test results collected in the database and the re-evaluation according to section 2. The new experimental investigations described in the previous section are classified, too.

\subsubsection{Weld root failure of cruciform and T-joints}

Owing to the two possible locations of crack initiation in weld connections without full penetration, the assessment of the specimens is only possible in the case of complete test documentation. Therefore, the re-evaluation of detail 3 only includes test results with critical weld root failures. Furthermore, the $S$ - $N$ curve (Fig. 11) only considers those experimental data that match the following filter criteria:

- Location of stress determination (e.g. baseplate or weld cross-section) known

- No post-weld or heat treatment
- No coating of the semi-finished sheets (e.g. shop coating, zinc coating, etc.)

- Test specimens never exposed to corrosive media (e.g. seawater)

- Experimental data exclusively from primary sources

- Series with at least five meaningful tests results

- Only tests in the pulsating range $(0.0 \leq R<1.0)$

With over 400 test results, the filtered data collection covers a large range of influencing parameters, such as different sheet thicknesses, weld types (fillet and partial penetration DHY welds), weld thicknesses, different manufacturing influences, etc. Owing to the lack of information on the actual throat thicknesses, weld stresses are referred to the nominal throat thicknesses. However, for welding processes with deep penetration, e.g. submerged arc welding, the penetration depth is considered to avoid an overestimation of fatigue strength. An overall evaluation (Fig. 11) with the prediction interval, as explained in section 2 , and a fixed regression line slope $(m=3)$ confirms FAT $36\left(\Delta \sigma_{\mathrm{C}}=38 \mathrm{~N} / \mathrm{mm}^{2}\right)$. Despite extensive filter criteria, it is particularly noticeable that there is a high scatter of individual test results, which has a decisive influence on the low classification of detail 3 .

A closer look at the single test series shows that individual tests have a significantly shorter fatigue life, which can also be described with an increased distance from the regression line compared with other tests of the series. These "outliers" prove to be characteristic of this detail and may be explained by the weld root itself. At the weld root, unrecognized weld imperfections, especially lack of root fusion, may lead to premature crack initiation in this area. In contrast to the failure areas on the surface of the specimen, visual testing cannot be used to detect weld imperfections, and for crack initiation at the root, the use of non-destructive test methods is very limited, too. The design engineer has to consider that during the structure's lifetime, a fatigue crack initiating at the weld root can

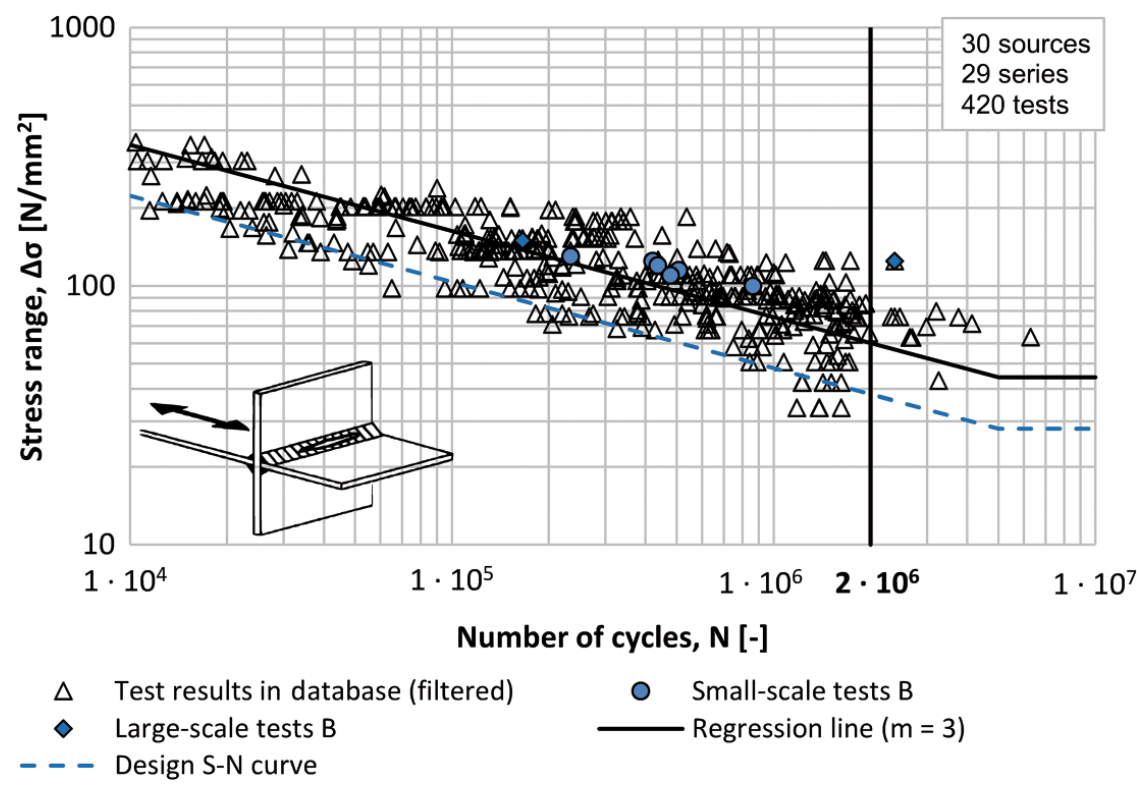

Fig. 11 Detail 3: filtered test results with weld root failure and classification of test series B [5] 
only be determined when it reaches the weld surface. At this point crack size may already be considerable, which may be regarded as a criterion for exclusion according to the detail application and necessary safety level.

In addition to weld imperfections, such as lack of root fusion and incomplete root penetration, further fatigue influencing factors, e.g. residual stresses, mean stress dependence and size effects, are described in [36] for construction details with weld root failure. The mean stress dependence, which is traced back to residual compressive stresses in the weld root area in [36], is also shown qualitatively on the available filtered data collection. However, the data collection, which consists almost exclusively of tests on small specimens, does not allow clear quantitative conclusions. Experimental results for large specimens, which represent realistic residual stress states, are currently insufficient for detail 3 . Therefore, the evaluation for $0.0 \leq R<1.0$ is up for discussion and the current classification according to EN 1993-1-9 [1] with FAT 36* seems justified for safety reasons.

As the results of the newly tested small-scale specimens of series B show (section 5.2), the evaluation of this single test series of detail 3 might lead to a significantly higher fatigue classification because of fewer varying influencing parameters. In contrast, the large-scale specimens of series B provide different failure regions and much greater scatter caused by additional influencing parameters. Nevertheless, all new tests fit well into the scatter band of the filtered data collection shown in Fig. 11.

\subsubsection{Weld toe failure of cruciform and T-joints}

For the re-evaluation of the data collection of cruciform joints with critical weld toe failure, it is necessary to use comparable filter criteria as described in the previous sec- tion. Owing to the significantly lower number of tests matching these filter criteria, the influence of geometry was initially neglected and test specimens under bending stress permitted as well.

The $S$ - $N$ curve (Fig. 12) exhibits less scatter compared with detail 3 (Fig. 11). "Outliers" with a significantly shorter fatigue life occur significantly less frequently. An overall evaluation with the prediction interval (see section 2.3) and a fixed regression line slope $(m=3)$ gives a characteristic fatigue resistance $\Delta \sigma_{\mathrm{C}}=69 \mathrm{~N} / \mathrm{mm}^{2}$ at 2 million cycles. The available filtered data collection does not confirm FAT 80 according to EN 1993-1-9 [1]. The current database corresponds well with the FAT 71 classification according to the IIW recommendations [34].

Both small- and large-scale specimen test results of the $\mathrm{C}$ series (section 5.2) are in good agreement with the filtered data collection (Fig. 12). This is also supported by the individual tests of series $\mathrm{C}$ being closer to the regression line of the overall evaluation.

Furthermore, it can be seen that the geometric parameter range for detail 1 according to EN 1993-1-9 [1] is not covered by the previous test data collection, or only to a limited extent. For large plate thicknesses $t$ and wide spacing of the weld toe $l$ especially, the data collection does not contain representative test results, as can be seen from Fig. 13.

\section{6}

\section{Conclusion}

This paper presents the basic procedure of the current research project "Re-evaluation and enhancement of the detail catalogue in Eurocode 3" [5]. After explaining the statistical evaluation methods applied, a typical re-evalua-

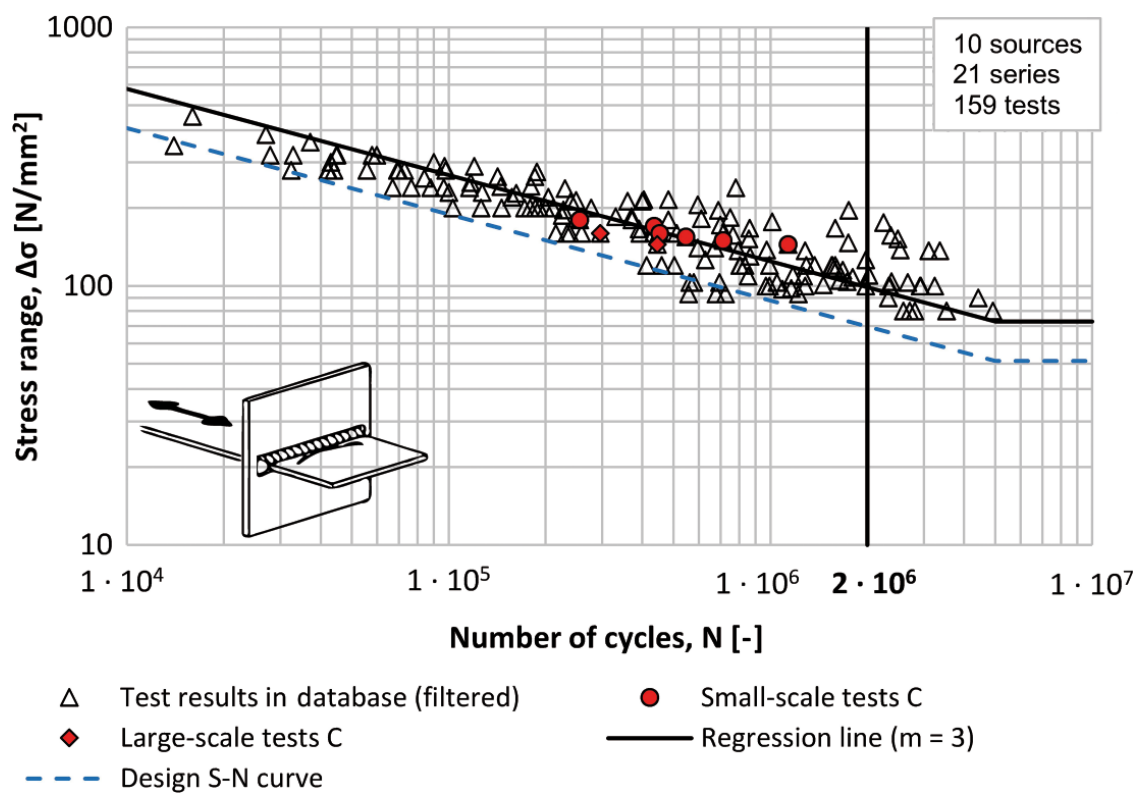

Fig. 12 Detail 1: filtered test results with weld toe failure and classification of test series C [5] 


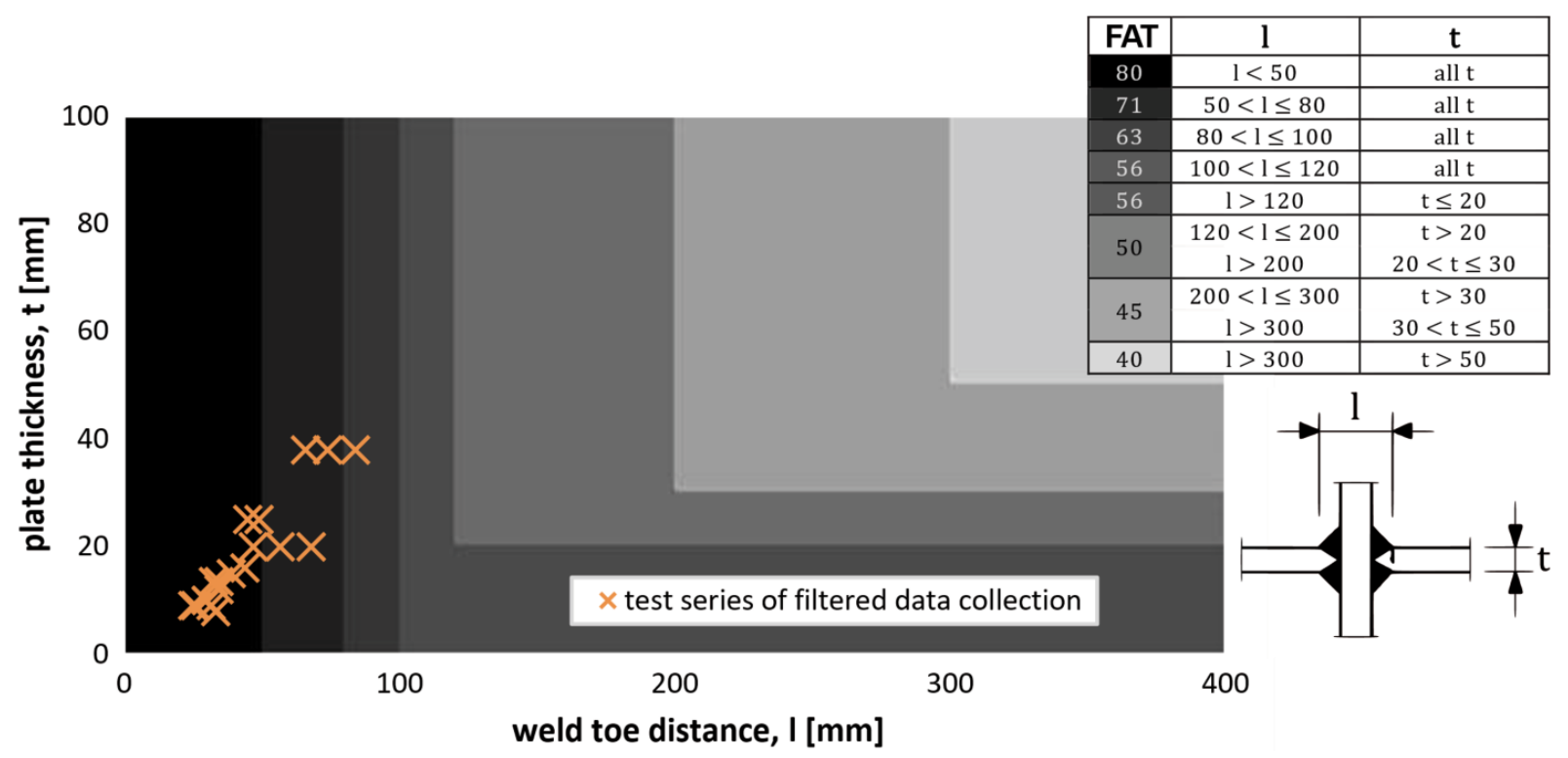

Fig. 13 Detail 1: parameter range covered by existing data (left) and corresponding classification of detail categories according to EN 1993-1-9 (right)

tion of the detail categories of longitudinal welds was presented with the help of collected fatigue data based on the background document to EN 1993-1-9 [21]. In a number of cases the evaluation showed that fatigue details should be reclassified. For example, automatic longitudinal welds with stop/start positions corresponding to detail 3 of Tab. 8.2 [1], see Tab. 3 in section 4.2, could be upgraded from FAT 112 to FAT 125. Similarly, for manual welds (detail 5), an improvement from FAT 100 to FAT 112 is possible on the basis of the available test data.

In addition, first results from experimental and numerical investigations have been presented. These are intended to simplify the fatigue verification of endplate connections with prestressed bolts. The test results comply very well with the evaluation of the T-joints and cruciform joints based on the newly established database.

In general, the analysis of the experimental data on which EN 1993-1-9 [1] is based has revealed the limitations of the available database for the classification of details despite a huge amount of research not only in structural but also mechanical engineering, all of which was considered in the database as far as available. Further, in the current detail catalogue the classification implies that some theoretical notch effects, which have not yet been confirmed experimentally, have an influence on the fatigue strength.

\section{Outlook}

As already mentioned, using the example of the T-joint (see section 5.4), some details are supposed to reveal an underlying size effect. In most codes and guidelines, as well as in EN 1993-1-9 [1], only simplified rules are considered for this purpose. Evaluations of experimental data for the design detail "longitudinal stiffener" show that the normatively assumed size influence tends to be overestimated and can thus lead to uneconomical dimensions.
EN 1993-1-9 [1], for example, allows for a degradation from FAT 80 to FAT 56 depending on the length of the longitudinal stiffener. The IIW recommendations [34] also take the plate thickness into account, leading to even worse detail classifications in the range of thick plates. Fig. 14 shows the scatter bands of the test series included in the database in relation to 2 million cycles depending on the length of the stiffener $L$. Obviously, the current fatigue class degradation does not adequately reflect the trend of the experimental data. Therefore, an improvement to the classification seems possible, especially for long stiffeners.

The test values shown in Fig. 14 were determined on plate thicknesses from 4 to $32 \mathrm{~mm}$. However, further experimental investigations to assess the mutual influence of longitudinal stiffener length and plate thickness, especially for the thick plates relevant for bridges, are currently lacking.

Apart from size influences, there is also a need for further research regarding the influences of production and tolerances. Manufacturing tolerances play a major role in the fatigue strength of welded structures, e.g. in the case of root gaps in T-joints and stiffeners (see Fig. 15). Welded joints can include manufacturing defects, metallurgical changes in the base material or internal irregularities, which are in fact partially covered by the existing fatigue details without notice. Lack of penetration at butt welds in T-joints or cruciform joints represent such an irregularity being referred to as root gap. Modern non-destructive testing methods can discover such gaps, which may then lead to discussions, as the current standards require proof of through-welding of butt welds. Generally, it seems possible to tolerate welds with limited gaps not only for predominantly statically loaded, but also for cyclically loaded structures. Corresponding investigations have already been carried out at RWTH Aachen University using fracture mechanics methods [37]. 


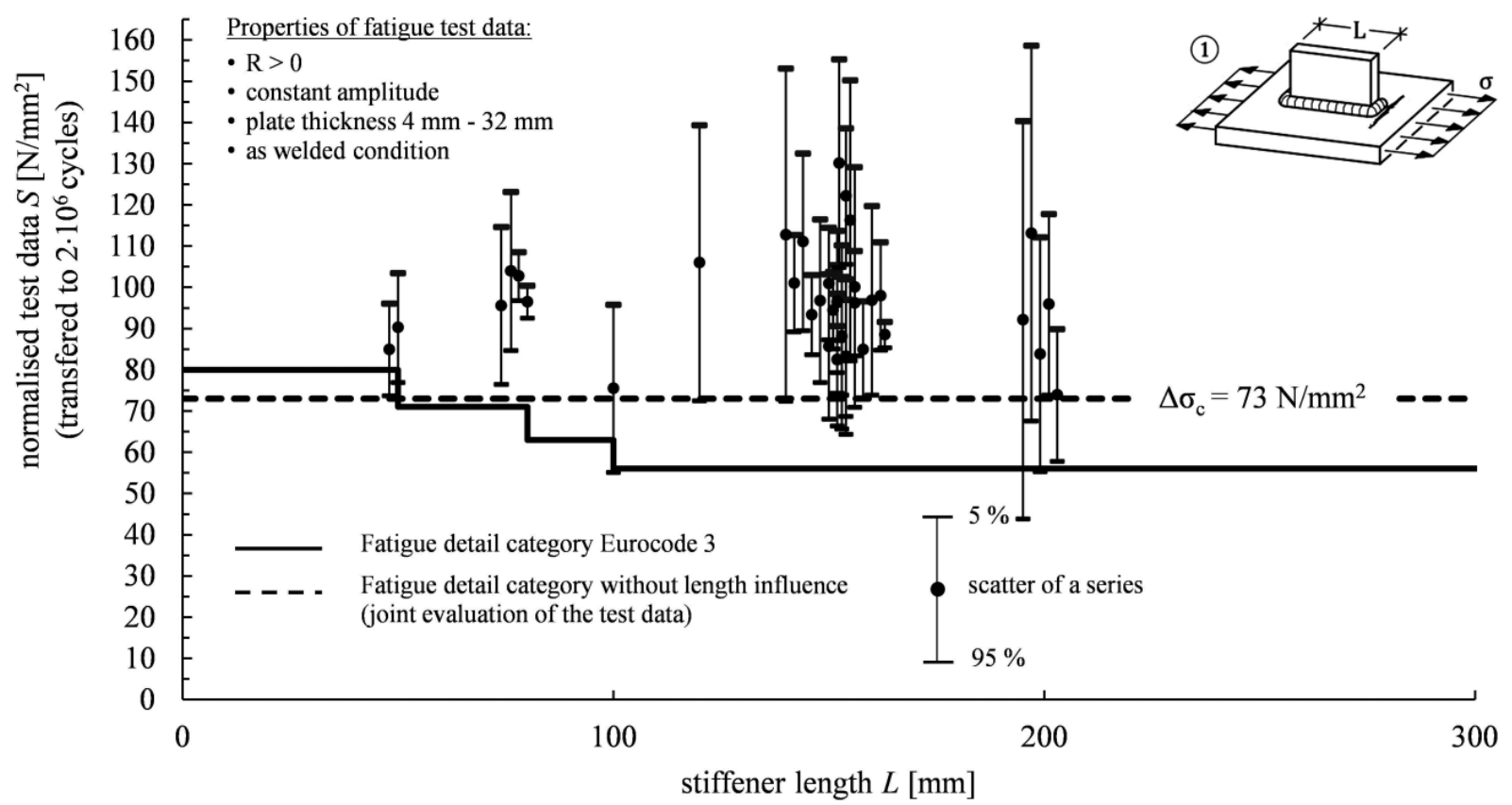

Fig. 14 Normalized scatter bands as a function of the length of the longitudinal attachment for test series collected in [5] (test data normalized to 2 million cycles)
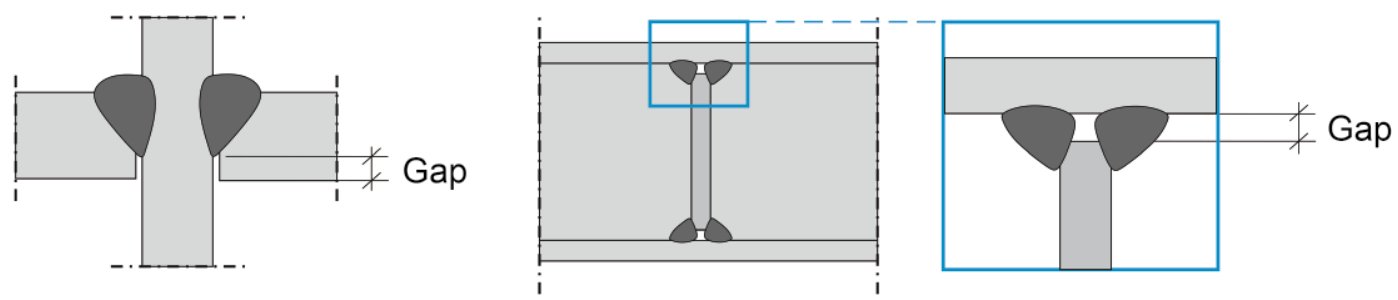

Fig. 15 Gaps in cruciform joints and stiffened beams

The same procedure may also be applied to assess the fatigue safety of stiffeners in rolled sections. Owing to tolerances in the dimensions of the rolled sections, full stiffeners may be fabricated too small, resulting in critical gap sizes. These gaps lead to stress concentrations in the weld area which may also be evaluated with local fatigue concepts.

As a further outlook regarding future research, the determination of fatigue strength using the notch stress concept should be mentioned, e.g. the simulations of the tests on the T-joint lead to differentiated, partially favourable results. Based on the database, such investigations may also be applied to other details in the future in order to improve the fatigue strength analyses with respect to economy and safety. Of course, the application limits of the effective notch stress concept, e.g. its limited application to details with high residual stresses or small stress gradients, must be considered here.

\section{Acknowledgements}

The investigations presented were carried out within the scope of the research project "Re-evaluation and enhancement of the detail catalogue in Eurocode 3" [5]. The project of the German Committee on Steel Construction (DASt) in cooperation with the Research Association for Steel Applications (FOSTA) was funded by the German Federation of Industrial Research Associations (AiF) within the scope of the programme for the promotion of Industrial Collective Research (IGF) of the Federal Ministry for Economic Affairs and Energy. The research institutions would like to express their thanks for this assistance. Special thanks also go to the AG der Dillinger Hüttenwerke, Peiner Träger GmbH, Freyler Industriebau $\mathrm{GmbH}$, August Friedberg $\mathrm{GmbH}$, Donges SteelTec $\mathrm{GmbH}$, Zwickauer Sonderstahlbau GmbH and the Max Bögl group of companies for providing the materials and fabricating the test specimens.

Open access funding enabled and organized by Projekt DEAL. 


\section{References}

[1] EN 1993 (2010) Design of steel structures - Part 1-9: Fatigue.

[2] DIN 4132 (1981) Kranbahnen; Stahltragwerke; Grundsätze für Berechnung, bauliche Durchbildung und Ausführung.

[3] DS 804, Druckschrift 804 (1980) Eisenbahnbrücken. Karlsruhe: Druckschriftenwerk der Deutschen Bahn AG.

[4] Feldmann, M.; Eichler, B.; Schaffrath S.; Stötzel J. (2013) Ermüdungsfestigkeitsnachweise für den Kranbau nach verschiedenen Regelwerken in: Stahlbau 82, no. 4, pp. 250-263.

[5] Feldmann, M.; Bartsch, H.; Ummenhofer, T.; Seyfried, B.; Kuhlmann U.; Drebenstedt, K. (2020) Re-evaluation and enhancement of the detail catalogue in Eurocode 3 for future oriented design of steel construction under high loading - Final Report.

[6] Bartsch, H.; Feldmann, M. (2018) Assessment of fatigue tests to review detail categories of EC3. IABMAS, Melbourne.

[7] Drebenstedt, K.; Euler, M. (2018) Statistical Analysis of Fatigue Test Data according to Eurocode 3. IABMAS, Melbourne.

[8] Feldmann, M.; Bartsch, H.; Kuhlmann, U.; Drebenstedt, K.; Ummenhofer T.; Seyfried, B. (2019) Auswertung von Ermüdungsversuchsdaten zur Überprüfung von Kerbfallklassen nach EC3-1-9 in: Stahlbau 88, no. 10, pp. 1004-1017.

[9] Bartsch, H.; Hoffmeister, B.; Feldmann, M. (2019) Investigations on the fatigue behavior of end plate connections with prestressed bolts in: Procedia Structural Integrity 19, pp. 395-404.

[10] Bartsch, H.; Hoffmeister, B.; Feldmann, M. (2020) Fatigue analysis of welds and bolts in end plate connections of I-girders in: International Journal of Fatigue 138, 105674. https://doi.org/10.1016/j.ijfatigue.2020.105674.

[11] Brozetti, H.; Hirt, M.; Ryan, I.; Sedlacek, G.; Smith, I. (1998) Background information on fatigue design rules Statistical evaluation - Chapter 9 - Document 9.01, 1st draft. Eurocode 3 - Editorial Group.

[12] Hobbacher, A. (1975) On evaluation of fatigue test data. IIW-Cov. XII-XV 15-75.

[13] D`Angelo, L.; Nussbaumer, A. (2017) Estimation of fatigue $S-N$ curves of welded joints using advanced probabilistic approach in: International Journal of Fatigue 97, pp. 98113.

[14] Lassen, T.; Darcis P.; Recho, N. (2005) Fatigue Behavior of Welded Joints Part 1 - Statistical Methods for Fatigue Life Prediction in: Supplement to the Welding Journal, pp. 183187.

[15] Caiza, P.; Ummenhofer, T. (2018) Consideration of the runouts and their subsequent retsts into $S-N$ curves modelling based on a three-parameter Weibull distribution in: International Journal of Fatigue 106, pp. 70-80

[16] EN 1990 (2002) Basis of structural design.

[17] Basquin, O. (1910) The exponential law of endurance tests. American Society for Testing and Materials Proceedings, no. 10 , pp. 625-630.

[18] Haibach, E.; Olivier, R.; Rinaldi, F. (1981) Statistical design and analysis of an interlaboratory prgram on the fatigue data for welded joints in structural steel. ASTM STP, vol. 744, pp. 24-54.

[19] Hahn, G.; Meeker, W. (1991) Statistical intervals - A Guide for Practitioners. New York: Wiley.
[20] Holicky, M. (1975) Basic statistical concepts and technique - Implementation of Eurocodes Handbook 2 Relia bility Backgrounds. Leonardo Da Vinci Pilot Project CZ/02/B/F/PP-134007

[21] Sedlacek, G. et al. (2016) Commentary to Eurocode 3 : EN 1993 - Part 1-9 - Fatigue (unpublished). Aachen.

[22] Background Documentation Chapter 9 (1989) Document 9.01 - Eurocode No. 3 - Design of Steel Structures Part 1 - General Rules and Rules for Buildings.

[23] EN ISO 2553 (2014) Welding and allied processes - Symbolic representation on drawings - Welded joints.

[24] EN ISO 6947 (2018) Welding and allied processes - Welding positions.

[25] EN ISO 4063 (2011) Welding and allied processes - Nomenclature of processes and reference numbers.

[26] Fisher, J. W.; Frank, K. H.; Hirt, M. A.; McNamee, B. M. (1970) Effect of weldments on the fatigue of steel beams. National Cooperative Highway Research Program, Report 102.

[27] Reemsnyder, H. S. (1963) Fatigue strength of longitudinal fillet weldments in USS „T-1“ constructional alloy steel. Fritz Engineering Laboratory Report No. 284.6.

[28] Olivier, R.; Ritter, W. (1981) Einfluß von Poren aus Fertigungsbeschichtungen auf die Schwingfestigkeit längsbeanspruchter Kehlnähte. Bericht Nr. FB-160, Laboratorium für Betriebsfestigkeit Darmstadt.

[29] Minner, H. H. (1981) Schwingfestigkeitserhöhung von Schweißverbindungen aus hochfesten Feinkornbaustählen StE 460 und StE 690 durch Einsatz des WIG-Nachbehandlungsverfahrens. [Dissertation] Technische Hochschule Darmstadt.

[30] Olivier, R. (1978) Untersuchungen zur Dauerschwingfestigkeit des Stahles St 52-3 an geschweißten I-Trägern. Bericht Nr. FB-91, Laboratorium für Betriebsfestigkeit Darmstadt

[31] Munse, W. H.; Stallmeyer, J. E. (1960) Influence of weld details on fatigue of welded beams and girders in: British Welding Journal 7, no. 3, pp. 188-200.

[32] Ruge, J.; Woesle, H. (1962) Ergebnisse von Dauerfestigkeitsuntersuchungen. Fachbuchreihe Schweißtechnik 23, pp. 59-68. Düsseldorf: Deutscher Verlag für Schweißtechnik $\mathrm{GmbH}$.

[33] Kuhlmann U.; Drebenstedt, K. (2020) Ermüdungsfestigkeit von Gurtlamellenenden in: Stahlbau 89, no. 3, pp. 229-239.

[34] Hobbacher, A. F. (2016) Recommendations for Fatigue Design of Welded Joints and Components - Second Edition IIW document IIW-2259-15 ex XIII-2460-13/XV-1440-13 International Institute of Welding, Springer International Publishing Switzerland.

[35] Sonsino, C. M.; Fricke, W.; d. Bruyne, F.; Hoppe, A.; Ahmadi A.; Zhang, G. (2012) Notch stress concepts for the fatigue assessment of welded joints - Background and applications in: International Journal of Fatigue 34, pp. 2-16.

[36] Maddox S. J. (2008) Status Review on Fatigue Performance of Fillet Welds in: Journal of Offshore Mechanics and Arctic Engineering 130, no. 3, pp. 1-10, August.

[37] Feldmann, M.; Eichler B.; Höhler, S. (2009) Eine Methode zur Bewertung von Restspalten in Schweißnähten an Tund Kreuzstoßverbindungen in: Stahlbau 78, no. 4, pp. 243252. 


\section{Authors}

Helen Bartsch, M.Sc. (corresponding author)

h.bartsch@stb.rwth-aachen.de

RWTH Aachen University

Institute of Steel Construction

Mies-van-der-Rohe-Str. 1

52074 Aachen, Germany

Karl Drebenstedt, M.Sc. (IWE)

karl.drebenstedt@ke.uni-stuttgart.de

University of Stuttgart

Institute of Structural Design

Pfaffenwaldring 7

70569 Stuttgart, Germany

Benjamin Seyfried, M.Sc. (IWE)

benjamin.seyfried@kit.edu

Karlsruher Institute of Technologie (KIT)

Steel \& Lightweight Structures

Otto-Ammann-Platz 1

76131 Karlsruhe, Germany

Prof. Dr.-Ing. Markus Feldmann

feldmann@stb.rwth-aachen.de

RWTH Aachen University

Institute of Steel Construction

Mies-van-der-Rohe-Str. 1

52074 Aachen, Germany
Prof. Dr.-Ing. Ulrike Kuhlmann

Sekretariat@ke.uni-stuttgart.de

University of Stuttgart

Institute of Structural Design

Pfaffenwaldring 7

70569 Stuttgart, Germany

Prof. Dr.-Ing. Thomas Ummenhofer

thomas.ummenhofer@kit.edu

Karlsruher Institute of Technologie (KIT)

Steel \& Lightweight Structures

Otto-Ammann-Platz 1

76131 Karlsruhe, Germany

\section{How to Cite this Paper}

Bartsch, H.; Drebenstedt, K.; Seyfried, B.; Feldmann, M.; Kuhlmann, U.; Ummenhofer, T. (2020) Analysis of fatigue test data to reassess EN 1993-1-9 detail categories. Steel Construction 13, No. 4, pp. 280-293. https://doi.org/10.1002/stco.202000019

This paper has been peer reviewed. Submitted: 18. March 2020; accepted: 27. August 2020. 